\title{
Understanding what was said
}

\author{
Guy Longworth ${ }^{1}$
}

Received: 26 July 2016 / Accepted: 4 October 2016 / Published online: 12 October 2016

(C) The Author(s) 2016. This article is published with open access at Springerlink.com

\begin{abstract}
On the most prominent account, understanding what was said is always propositional knowledge of what was said. I develop a more minimal alternative, according to which understanding is sometimes a distinctive attitude towards what was said-to a first approximation, entertaining what was said. The propositional knowledge account has been supported on the basis of its capacity to explain testimonial knowledge transmission. I argue that it is not so supported.
\end{abstract}

Keywords Understanding · What is said · Knowledge

\section{Introduction}

The capacity to understand what people say supports a momentous extension of one's knowledge-gathering powers. Most importantly, it enables one to acquire knowledge at second hand from others' testimony. In the absence of that ability, our intellectual lives would be, at best, radically impoverished. The capacity can also provide one with knowledge about speakers, through making available to one their expressions of psychological states and episodes. And, of course, the capacity can enable one to know what people say. The ability to understand is one of our central epistemic powers. For that reason, it has been common to treat the outputs of exercises of that ability-states of understanding what someone said-as propositional knowledge about what they said. In opposition to that treatment, I defend the entertaining account, according to which understanding what someone said consists in entertaining the proposition they expressed, rather than in entertaining a proposition about that proposition.

\footnotetext{
Guy Longworth

g.h.longworth@warwick.ac.uk

1 University of Warwick, Coventry, UK
} 
In many cases, it's plausibly a necessary condition on coming to know something on the basis of what someone says that one hears, or otherwise perceives, their utterance. But it's possible to hear an utterance without understanding it, even if one is competent with the language. Moreover, it seems possible to grasp the meanings of words and sentences that were used in an utterance without yet understanding what was saidfor example, where those sentences involve demonstratives or other context-sensitive expressions. What does understanding what was said add to hearing utterances and grasping their linguistic meanings? According to the most prominent account, which I'll refer to as the propositional knowledge account, understanding what someone said when they said that $p$ consists invariably in acquiring a piece of propositional knowledge to the effect that they said that $p$ (Campbell 1982; Dummett 1978, 1991; Davies 1989; Evans 1982; Heck 1995; Higginbotham 1992; McDowell 1994). In what follows, I present reasons for thinking that understanding can take other forms and that it is possible to understand what was said without knowing what was said.

One problem for the propositional knowledge account is that it's plausible that one can know what a speaker said without understanding their utterance, for instance in cases in which one comes to know what they said on the basis of subtitles or other forms of testimony. More carefully, it's plausible that there are basic forms of understanding that are absent in such cases (see Hunter 1998; Pettit 2002; Fricker 2003). One kind of account that avoids that difficulty holds that understanding an utterance is a specific way of knowing, just as seeing that such-and-such and remembering that such-andsuch are specific ways of knowing. On this account, understanding what someone said requires knowing what they said in a specific way, where that way is not present-or not clearly present-in cases in which one knows what someone said on the basis of subtitles or testimony.

A minimal view of seeing that such-and-such is that it amounts to knowing that suchand-such on the (perhaps concurrent) basis of seeing. And one can see something-for instance, a desk, covered in papers - without seeing that the desk is covered in papers. A minimal view of understanding, analogous to the treatment of seeing, would be the following. Understanding that someone said that $p$ is a matter of knowing that they said that such-and-such on the (perhaps concurrent) basis of understanding what they said. On such a view, understanding what was said is treated, like seeing, not as a way of knowing, but as a distinct state that is capable of providing the initial grounds for pieces of knowledge. Should we allow that, as in the case of seeing, it's possible to understand what someone said without knowing that they said it?

Where a speaker said that $p$, taking in what they said plausibly requires that one comes to bear attitudes towards the proposition that $p$ - that one comes in some appropriate way to entertain that proposition. And one way of doing that might be to come to know that the speaker said $p$. However, it's plausible that one might take in what someone said in a case in which one had apparent grounds to believe that one was hallucinating, or had misleading (apparent) evidence that the speaker couldn't have said what they appeared to say. In such cases, one's (apparent) grounds or evidence might prevent one from knowing that the speaker said that $p$, but would nonetheless be consistent with one's understanding what they said. That would align the case of understanding what was said with that of seeing objects, since one can see objects while precluded — for example, by misleading apparent evidence-from knowing that 
they are there. In what follows, I draw on a partial analogy with object-directed seeing in order to develop an account on which understanding is possible in the absence of propositional knowledge of what was said.

The propositional knowledge account of understanding finds support from two functions of understanding in sustaining the acquisition of knowledge: its function in sustaining knowledge of what was said; and its function in sustaining knowledge gained on the basis of what was said.

When we judge that an auditor understands what a speaker said, we are ordinarily willing to judge that they know what the speaker said. And it's plausible that an audience knows what a speaker said just in case, for some fact to the effect that the speaker said that $p$, the audience knows that fact. Hence, we are ordinarily willing to infer from the fact that an auditor understands what a speaker said, in a case in which the speaker said that $p$, that the auditor knows that the speaker said that $p$. However, our willingness to reason in that way doesn't show that the propositional knowledge account is correct. Our judgments might be due not to tacit acceptance of the propositional knowledge account, but rather to our sensitivity to the way that understanding non-constitutively, but reliably, gives rise to knowledge, at least amongst typical adults. Compare here the fact that when we judge that a typical adult sees a cat, we are ordinarily willing to judge that they know that there's a cat there, despite the fact that we would also accept that it's possible to see a cat without recognizing it as such.

A more powerful seeming argument in support of the propositional knowledge account arises from the function of understanding in the transmission of knowledge by testimony. In preliminary form, the argument is this. There seem to be cases with the following pair of properties. First, they are cases in which knowledge is transmitted via testimony. Second, they are cases in which the audience's understanding of testimony could only facilitate their acquisition of knowledge if understanding met appropriate epistemic conditions. Driving the consideration is the thought that if understanding had a lesser epistemic status than knowledge, or had a status that failed to put one who understood in a position to know what was said, then it would impose that lesser status as an upper bound on any states that were acquired on its basis. In that case, understanding what someone said would seem to preclude, rather than facilitate, the transmission of knowledge. Consider, for example, a case in which one believed correctly that a speaker said that smoking is dangerous and came, on the basis of that belief together with knowledge that one's interlocutor spoke truly, to believe that smoking is dangerous. If one's belief about what was said failed to amount to knowledge- - for example, if it were formed on the basis of a lucky guess-then it is plausible that one's belief that smoking is dangerous would not amount to knowledge. Hence, it is plausible that the understanding operative in such cases must suffice for knowledge of what was said. (Versions of this argument are presented in Dummett 1978; Evans 1982, pp. 310-311; Heck 1995.) Again, however, the analogy with seeing can help us to see ways of responding to this type of argument. It's plausible that although seeing an object is not a form of knowing, it typically puts one in a position to know. Similarly, the sketched argument fails to rule out that understanding an utterance can put one in a position to know things without itself being a form of knowledge.

My aim here is to exploit gaps in the sketched argument for the propositional knowledge account in order to make out the possibility of an alternative account, the 
entertaining account. I begin (Sect. 2) by developing the entertaining account in more detail. Then, in Sect. 3, I return to the role of understanding in facilitating the transmission of knowledge by testimony. I argue that the propositional knowledge account is not supported by its capacity to figure in explanations of testimonial knowledge transmission. I propose a treatment of knowledge transmission that embeds the alternative, in my view superior, entertaining account of understanding. That serves to undercut the purported justification for the propositional knowledge account. Furthermore, it does so in a way that exhibits the advantages of the alternative account over accounts that, like the propositional knowledge account, make understanding a form of cognition about what is said, rather than a way of entertaining the propositional content of what was said. In Sect. 4, I briefly compare the entertaining account with alternative accounts proposed by Pettit (2002) and Fricker (2003).

\section{An entertaining account}

Understanding what a speaker said determines, from the audience's perspective, that the speaker said what they did. In doing so, it performs two tasks. First, it determines, in the following sense, that the speaker said what they did: one couldn't be in the same state of understanding in a case in which the speaker did not say what they did. Second, it performs the first task in a way that enables the speaker's saying what they did to shape the audience's perspective. Since knowledge is factive- that is, since knowing that pentails $p$-the propositional knowledge account deals with the first task. And since knowing is a state of mind, or is closely bound up with occupying specific states of mind, it plausibly deals with the second.

How could psychological states or episodes other than states of propositional knowledge determine facts about what a speaker said? Consider here how the perception of objects can function in the acquisition of knowledge. In propitious circumstances, seeing an object, and its particular features and activities, can put suitably equipped subjects in a position to know that the object is present, and that it is disposed in one or another way. Consider a subject who is equipped with the concept chair together with an ability reliably to deploy that concept in response to what they see. In propitious circumstances, seeing a chair can put such a subject in a position to know that a chair is present. Plausibly, this is because seeing a chair is knowledge enabling. Seeing a chair is impossible unless there is a chair there to be seen. Seeing a chair provides a guarantee, from the subject's perspective, of the chair's presence. The chair's presence in turn guarantees the fact that the chair is present. Seeing the chair thus underwrites a necessary condition on being in a position to know that the chair is present, by determining, from the subject's perspective, the fact that the chair is present. If one is to know that there is a chair there, what is required in addition to merely seeing the chair is the appropriate exercise of suitable conceptual capacities-capacities that exploit the perceived presence of the chair in order to furnish one with reliable propositional cognition of the chair and its location (see e.g. Kalderon 2011).

What would be an analogous account of understanding as a basis for knowledge of what was said? Here, in five stages, is a sketch of such an account, the entertaining account. The entertaining account begins (at stage one) from reflection on subjects' 
abilities to have in mind, and bring to mind, propositional contents. Normal human subjects are able to think a variety of propositional contents. For example, they may be able to think, or entertain, the propositional contents that it's raining, that smoking is dangerous, or that second-order logic is existentially committing. Subjects can also bring to mind such contents, as when they suppose that, or wonder whether, or idly consider how. I'll use 'think', 'entertain', and their cognates as generic terms for the various propositional attitudes or cognitive modes involved in engaging propositional contents.

Such thinking is classifiable both by appeal to the propositional contents that it engages and by appeal to the general types of attitude that it involves. Focusing on the first dimension, one might associate episodes of thinking with the propositional content that smoking is dangerous and distinguish them from those that engage the proposition that second-order logic is existentially committing. Focusing on the second, one might associate episodes of thinking that engage a propositional content in the mode of supposing, and distinguish them from episodes of wondering, idly considering, and so forth. The classification picks up on functional or explanatory differences in the ways that various forms of thinking shape, and are shaped by, the rest of a subject's cognitive economy. And corresponding to the two dimensions of classification are a range of different abilities - for example, the (possibly complex) ability to have attitudes to the propositional content that smoking is dangerous and the ability to suppose things.

The first stage of the account appeals to the idea that some of the abilities exercised in actively bringing contents to mind can also be triggered in other ways. If one is suitably equipped, then one's abilities to think a propositional content can be triggered from without by one's being confronted, in perception, with an utterance that bears that content. Thus, perceptual confrontation with an utterance can bring it about that one engages a particular content, that one thinks it. For instance, a competent English speaker's perception of an utterance of "Smoking is dangerous" might bring it about that they entertained the proposition that smoking is dangerous. That way in which the exercise of one's thinking abilities can be triggered determines a particular range of propositional attitudes. Members of the range bear the functional mark of their having been triggered, or seemingly triggered, by confrontation with an utterance or some other concrete bearer of the content. The functional or explanatory roles of outputs of such externally triggered exercises of thinking abilities will differ from the roles of otherwise similar outputs that are not externally triggered, or whose instances are not of a nature to be externally triggered in that way. (The functional difference here is broadly analogous to that between sensory experience and sensory imagination. For present purposes, we can remain neutral about the explanatory, as opposed to expository, priority of active vs. externally triggered entertaining.) I'll say more about the functional or explanatory differences between the target range and other types of attitude below.

Thus far, we have the idea that there are propositional attitudes that are triggered by perceptual encounters with utterances. That idea doesn't require that the contents of such attitudes converge with contents expressed in the triggering utterance. But understanding an utterance does require that one engage the content expressed by the utterance. The second stage of the account aims to ensure that the mode of engagement to which it appeals meets this additional condition. The result is secured by 
imposing an additional requirement on the attitudes that constitute understanding. In addition to being triggered by perceptual confrontation with a concrete vehicle, those attitudes must be triggered - or by nature apt to be triggered - by confrontation with an appropriate vehicle, one that in fact bears the content that's so engaged. (It's plausible that the standing properties of a sentence do not determine all of the contents borne by utterances of it. The machinery that enables subjects to meet this condition must therefore be sensitive to the effects of other-broadly pragmatic-determinants.)

The third stage of the account specifies in more detail the attitudes that constitute understanding. Crucially, the generic attitude that constitutes understanding is a form of first-order engagement with the propositional content expressed in an utterance, a way of thinking that very content, as opposed to thinking about that content. That is, it's a mode of engagement with what was said, rather than a mode of engagement with a different content that presents what was said as having been said. Believing that smoking is dangerous differs from believing that it has been said that smoking is dangerous. The former belief is apt to make a committed smoker question their practices, while the latter is apt only to make them question their sources. Similarly, understanding it to have been said that smoking is dangerous differs from engaging the content that it has been said that smoking is dangerous. The latter mode of engagement is immediately with the content that it has been said that smoking is dangerous, and only derivatively with the content that smoking is dangerous. Thinking that it has been said that smoking is dangerous might have as a necessary condition that one engages the content that smoking is dangerous at first-order. (That would be an upshot of, for example, Tyler Burge's Principle and Stronger Principle for Canonical Names of Senses (2005, 174ff).) But the attitude to the content that it has been said that smoking is dangerous will typically differ from the mode of first order engagement that it necessitates. This is so for reasons analogous to those responsible for the fact that engaging the content that smoking is dangerous as a merely necessary condition of believing that it has been said that smoking is dangerous and is not a way of believing that smoking is dangerous. As will be explained more fully in Sect. 3, this is the most fundamental difference between the entertaining account and the propositional knowledge account. Unlike the entertaining account, the propositional knowledge account treats understanding as a mode of entertaining a proposition about expressed propositions, and so a mode of entertaining expressed propositions at second order.

The first-order propositional attitude that is instigated on the basis of perceptual confrontation with appropriate vehicles can be characterized loosely in English as understanding, or as understanding it to have been said. For instance, confrontation with an utterance of the sentence, "Smoking is dangerous," might lead a subject to understand it to have been said that smoking is dangerous. We can leave open whether that characterization is entirely appropriate; for present purposes, it can be treated as a partial stipulation. One way in which the characterization in terms of understanding it to have been said is inappropriate is in carrying the suggestion that the attitude so characterized is somehow composed from more basic forms, that it involves understanding targeted onto it having been said, with the latter targeted onto the propositional content of a saying. That suggestion is rejected by the entertaining account, on which the attitude of understanding is targeted immediately onto the latter propositional content. 
Another way in which the characterization requires careful handling will be mentioned below.

Making use of a suitably broad notion of object, we can view the target propositional attitudes, like other such attitudes, as directed towards a special range of propositional objects, in this case expressed propositional contents. (Important defenses of treatments of propositional attitudes in general as object-directed may be found in King 2002 and Schiffer 2003. However, the entertaining account need not be bound to any specific treatment of attitudes and is compatible with any treatment that distinguishes thinking a proposition from thinking about a proposition. Thus, it is compatible with alternative treatments presented by, e.g., King et al. 2014; Moltmann 2003; Pietroski 2000; Pryor 2007; Rosefeldt 2008.) So viewed, attitudes of understanding are in some ways akin to seeing an object. In the cases both of seeing an object and understanding what was said, it is crucial to distinguish between being in a (potentially cognitively rewarding) relation to a thing, and being in an attitudinal relation to a thought that involves a certain concept of that thing. In the case of seeing, one may see a cat without having propositional knowledge that the cat exists; similarly one can understand what someone who said that $p$ said without knowing that someone said that $p$, where the latter piece of knowledge is about the proposition that $p$. However, quite different forms of psychological equipment are required in order to stand in the relation of understanding to what was said than are involved in, for example, seeing a cat. One must have a suitable range of sense-perceptual capacities in both cases. But in the case of understanding, unlike the case of seeing an object, one must possess a specific range of conceptual resources, abilities to entertain in one's thinking the specific contents of target utterances. And one must possess the ability to have those resources triggered through perception of an appropriate utterance, an ability that includes competence with the syntactic, semantic, and pragmatic factors that shape what utterances of that type can be used to say. For another difference, seeing a cat typically involves awareness of some aspects of the cat's appearance, while engagement with propositional content involves no analogous awareness of appearances of the propositional content. The process through which one comes to engage a propositional content in understanding may involve awareness of appearances of an utterance through which the propositional content is engaged. But such appearances are not appearances of what is engaged, the propositional content. For propositional contents are abstract in such a way that they lack straightforward analogues of perceptible appearances $(\mathrm{Cp}$. Church 1951, p. 104).

Like other forms of intellectual or perceptual engagement with environmental objects-for instance, cases of propositional knowing or of seeing objectsunderstanding something to have been said is subject to various requirements in addition to those already outlined. The requirements apply both to subjects and also to their relations to their environments. The fourth stage of the account involves saying something about those requirements. For present purposes, we can leave somewhat open the precise form taken by the pertinent requirements. But if understanding something to have been said is to sub-serve the acquisition and transmission of knowledge then it will be subject to a range of broadly epistemic requirements.

One such requirement is that understanding something to have been said is environment involving, in the following specific way: one cannot understand it to have been 
said that $p$ unless it has been said that $p$. (This is another way in which our theoretical notion might appear to differ from English 'understanding it to have been said', since the latter seems to allow for misunderstanding of various sorts, for states of merely seeming understanding.) Indeed, a stronger condition is plausible: one cannot understand it to have been said that $p$ unless one instances a mode of engagement with the proposition that $p$ that was appropriately shaped by confrontation with an utterance in which that proposition was expressed. (We can leave open here whether such shaping is constitutive or merely causal.) A related demand, again deriving from the connections that understanding has with knowledge, is that the outputs of exercises of one's ability to understand should correlate safely with what was in fact said in one's presence. At least in cases where understanding can give rise to knowledge, there should not be too much danger that, in threateningly similar circumstances, it would have seemed to one that one understood something to have been said that had not in fact been said. However, since knowledge arises through the combined exercises of the power of understanding and conceptual abilities, only the combination as a whole is required to meet such conditions on knowledge. It may be that the contribution of understanding to the transaction requires it to meet conditions distinct from the safety condition on knowledge. Perhaps, for example, what was said must figure constitutively in one's understanding, where that's consistent with there being significant danger of one's suffering a mere ringer for understanding proper. For present purposes, the main point is that the required conditions will correspond, in appropriate ways, with at least some requirements on knowing that someone said that $p$. To that extent, it is natural to expect that the requirements will track-or bear close analogies with-requirements on seeing objects. For both seeing and understanding involve engagement with features of one's environment that can support the acquisition of knowledge, at least in otherwise propitious circumstances and for subjects in possession of suitable cognitive equipment (for relevant discussion, see again Kalderon 2011).

According to the entertaining account, understanding what was said can take the form of first-order engagement with what was said-a propositional attitude with a propositional content that was expressed in one's presence. It's a specific form of engagement with such content, the upshot of exercises of an ability to have such engagements triggered by perceptual confrontation with appropriate utterances. And it is a form of engagement that meets broadly epistemic requirements, akin to requirements on seeing objects. To a good first approximation, it is a form of engagement with what was said suitable to put those who enjoy it in a position to know what was said. But it will give rise to such knowledge only amongst subjects who meet conditions in addition to those required for bare understanding.

The conditions on acquiring propositional knowledge of what was said outstrip those on understanding what was said in at least three ways. First, in order to acquire knowledge on the basis of understanding, subjects must have an appropriate conceptual repertoire. In particular, they must have a concept of saying (or a suitably correlative concept) together with a range of concepts that enable them to think, at second order, about the propositional content that they engage at first order through understanding. So, in order to know on the basis of understanding that it has been said that smoking is dangerous, a subject must have and exercise not only an ability to entertain the proposition that smoking is dangerous, but also an appropriate ability to think about 
saying and an appropriate ability to think about the propositional content that smoking is dangerous. Second, in order to acquire knowledge subjects must have abilities to apply the required range of concepts appropriately in their specific circumstances. It is not enough that subjects have an ability to think thoughts about what is said. They must in addition be able reliably to form correct beliefs or judgments about what was said in presented episodes of speech. Third, in order to come to know what was said on an occasion, subjects must exercise the relevant abilities in ways that meet operative epistemic standards. Their abilities must be exercised properly, in a way that is suitably sensitive to potential defeating conditions and the like. Subjects who understand what was said and who meet the additional conditions with respect to what was said can thereby come to know what was said.

Amongst typical adult humans, the respective requirements on bare understanding and on possession of knowledge will run in step. Typical adult humans possess the conceptual and applicational abilities required for acquiring knowledge of what was said across a range of circumstances. The account therefore provides support for the pattern of ordinary judgment linking understanding and propositional knowledge with which we began. But similarly, a typical adult human who sees a cat will know that there is a cat before them. In neither case does the normal acceptability of the form of inference show that the input conditions are forms of knowledge.

The propositional knowledge account has it that our cognitive and epistemic states determine what was said in our presence by determining our standing with respect to a proposition about what was said. By contrast, the present account has it that our cognitive and epistemic states determine what was said in our presence by determining a particular kind of standing with respect to what was said, a standing that one can have only as a distinctive kind of response to that propositional content's having been expressed in one's presence. Rather than seeking to explain understanding by appeal to a generic attitude of knowing together with a distinctive range of contents about what was said, the entertaining account places more of the explanatory burden on the distinctive type of attitude involved in understanding. That enables the entertaining account to treat understanding as a form of immediate cognitive engagement with what was said, rather than a form of indirect engagement via knowledge that it was said.

Plausibly, there are limits to the load-bearing capacity of the attitude dimension. It would be implausible to build the identification of specific sources of what is understood - that is, the identification of particular speakers, occasions of speaking, or utterances - into distinctions amongst attitudes so that, for example, understanding what Peter said involved a different attitude from understanding what Paul said (assuming that Peter $\neq$ Paul). Moreover, the ability of one who understands what was said to identify their sources seems to play an essential role in accounting for cases of testimony. The issues here are delicate and I can't pursue them in detail. However, there is no immediate reason to think that they constitute a threat to the entertaining account. For present purposes, we can take it that a complete account of the required abilities will make appeal to the integration of states of bare understanding as characterized here with sensory perception of sources or episodes of speech that are so understood (for further discussion, see Longworth 2008b). 
The fifth stage of exposition focuses on understanding assertions and further develops the analogy between seeing objects and understanding utterances. It's natural to characterize seeing an object as providing an invitation to belief in that, despite the possibility of withholding belief, seeing an object is not neutral with respect to how things are in one's local environment. Rather, seeing an object will typically induce one to treat one's environment as though the object were as it appears. Amongst suitably equipped subjects, so treating one's environment involves believing it to be as it appears. Seeing an object does not merely indicate to one the possibility of so believing. Seeing has authority over belief. Similarly, in understanding an assertion, one is presented with an invitation not only to form beliefs about what the speaker has said, but also to believe that one's environment is as the assertor thereby presents it. If the assertion is to the effect that smoking is dangerous, then understanding it provides one with an invitation to believe that smoking is dangerous. Although understanding such an assertion involves engaging the content that smoking is dangerous at first order, it does not—or need not-involve accepting that content. It will not do so if one has, or if one takes oneself to have, sufficiently weighty reasons for doubting the competence or sincerity of the assertor. However, although it's possible to understand an assertion without accepting what is asserted, one's understanding indicates more than the mere possibility that things are as they have been asserted to be. With respect to cases in which one has no special reason for doubt, Michael Dummett's characterization is apt:

I go through no process of reasoning, however swift, to arrive at the conclusion that he has spoken aright: my understanding of his utterance and my acceptance of his assertion are one. (Dummett 1993, p. 419).

That tells us something about the cognitive role of understanding assertions. However, we can also understand what is said in, for example, questions and commands. The propositional knowledge account deals effortlessly with differences amongst these cases of understanding on the basis of the differences between knowing that someone has asserted that $p$, knowing that someone has asked whether $p$, and knowing that someone has commanded that $p$. And it might be thought that the entertaining account cannot capture the different cognitive roles of understanding what was said that are appropriate to utterances with those other forces. That thought would be premature, however. For the entertaining account can exploit the attitude dimension in order to capture the required distinctions. In doing so, it treats understanding assertions as the responsibility of one way of entertaining what was said, and understanding questions and commands as the responsibility of other ways of entertaining what was said. To a first approximation, the attitude distinctively involved in understanding questions provides invitations to act - that is, by answering the questions-while the attitude distinctively involved in understanding commands provides invitations to act, or to form intentions to act, in fulfillment of the commands. Although there is more to say about the cognitive roles of each of these ways of entertaining what was said, there is no immediate reason to suppose that this represents an issue of principle as opposed to detail. Furthermore, the issues of detail here arise just as much for the propositional knowledge account, pending a full analysis of the cognitive roles of thought about things said with the various forces. 
Let's recap. First, understanding is an attitude towards what was said that is triggered by perceptual confrontation with an utterance. Second, the content to which one bears that attitude must be a content expressed by the utterance that triggers one's engagement. Third, and centrally, the attitude constitutes a first-order mode of engagement with the expressed content. Fourth, the attitude is subject to broadly epistemic requirements, shaped in part by the fact that understanding can give rise to knowledge of what was said. Fifth, understanding assertions can present invitations to form beliefs about the wider environment in accord with what was asserted. It's clear, in outline, that the account is well placed to figure in explaining how understanding can give rise to knowledge. Crucially, and by contrast with the propositional knowledge account, the account treats understanding as a form of first-order attitude with what was said as its content, rather than an attitude to a content about what was said. In the next section, the importance of this difference between the present account and the propositional knowledge account is illustrated, and exploited, in a comparative assessment of the ways in which the two accounts deal with our engagements with bits of testimony.

\section{Comparative assessment of the two accounts}

The epistemological proximity of the two candidate accounts might lead one to think that if the entertaining account applied to a subject, then so would the propositional knowledge account. However, even if that were correct it would not follow that satisfaction of conditions in the entertaining account guarantees satisfaction of conditions in the knowledge account. And even if that were guaranteed, the relative explanatory priority of the two accounts would remain open. For example, it's consistent with the claim that all typical subjects of seeing thereby acquire knowledge about their surroundings that their seeing figures in explaining their knowledge, rather than being constituted by that knowledge. Similarly, it's consistent with the claim that all typical subjects of understanding thereby acquire knowledge that their understanding explains their knowledge and is not constituted by it. In that way, one might hold that seeing objects invariably gives rise to perceptual knowledge without viewing any further consequences of that knowledge as over-determined by the conjunction of seeing and knowledge, since the perceptual knowledge would be dependent upon the seeing. Similarly, one might hold that understanding invariably gives rise to knowledge without viewing the further consequences of the knowledge as over-determined.

There is, therefore, a significant obstacle in the way of attempts to defend the propositional knowledge account by appeal to the role of understanding in sponsoring testimonial knowledge. We saw earlier (Sect. 1) that such an attempt might be based on the claim that if understanding what was said were not a form of propositional knowledge, then it would block, rather than facilitate, the transmission of knowledge. However, showing that propositional knowledge of what was said figures essentially in the transmission of knowledge by testimony would not suffice for such a defense. In addition, it must be shown that the sort of attitude characterized by the entertaining account is inessential to the acquisition of knowledge of what was said. However, I propose to bypass that difficulty in order more directly to compare the treatments of testimony supported by the competing accounts. I'll argue that the entertaining 
account is capable of sustaining a treatment of testimony on which it can enable the transmission of knowledge even in the absence of propositional knowledge of what was said. And I'll argue that, by comparison with the entertaining account, the propositional knowledge account provides an over-intellectualized treatment of the role that understanding plays in accounting for the warranted acceptance of testimony.

Let's begin by considering a propositional knowledge based treatment of a subject's warrant for accepting what someone said. The account begins from (P1), the purported output of understanding what was said.

(P1) $A$ knows what $S$ said (i.e., $A$ knows that $S$ said that $p$ ).

Since our focus is on the role of understanding in testimonial warrant, rather than more general questions about the warrant for treating testimony as true, we can assume that $A$ has a knowledge sustaining warrant for accepting that what $S$ said is true:

(P2) $A$ knows that what $S$ said is true.

(P1) and (P2) then serve as lemmas for an inference, on the basis of which Acomes to accept what they were told, and so we reach $(\mathrm{C})$ :

(C) $A$ accepts what $S$ said (i.e., $A$ accepts that $p$ ).

What is required is an account of how the state of acceptance characterized in (C) can be warranted by the states of knowledge characterized in (P1) and (P2). The first piece of knowledge guarantees that $A$ 's view about what $S$ said reliably reflects what $S$ in fact said. The second secures warrant for accepting that what $S$ said is true. What is wanted, then, is an account of how those guarantees transmit to the state of acceptance characterized in (C). The most natural treatment is inferential. Since (C) is required to be inferentially dependent upon (P1) and (P2), we have the earlier advertised justification for the claim that the state characterized in (C) could amount to knowledge only if $A$ 's understanding of what was said also amounted to knowledge. (In fact, it's arguable that one might know that $p$ on the basis of inference in cases in which one doesn't know the premises of the inference. See e.g. Arnold (2013), Fitelson (2010), Klein (2008), Warfield (2005). Perhaps, for example, it is possible to come to know that $p$ by inference from the belief that everyone said that $p$ in cases in which the latter belief isn't (quite) true. Since allowing that possibility would only weaken the case for the propositional knowledge account, I propose to ignore it.)

The problem with this purported justification for the propositional knowledge account is that the inference connecting the states in (P1) and (P2) with the state in (C) is enthymematic. Our next task, then, will be to shore up that inferential connection. Doing so will help to reveal the extent to which the treatment is more intellectually demanding than a treatment based on the entertaining account.

Knowing what a speaker said is an unspecified form of knowing with a propositional object picked out by the complementizer phrase, 'what the speaker said'. To a close approximation, it's a matter of knowing that $p$, where $p$ is a full and correct answer to the question: 'what did the speaker say?' (For a closer approximation, see e.g. Karttunen 1977.) Where Flo said that smoking is dangerous, knowing what Flo said amounts to knowing that Flo said that smoking is dangerous, rather than knowing that smoking is dangerous. So, knowing what was said is not a form of first-order engagement with that which was said. By contrast, accepting what a speaker said is an 
attitude with a propositional content picked out by a nominal phrase or relative clause. It's a matter of accepting that $p$, where that pis identical with that which the speaker said. For instance, where Flo said that smoking is addictive, accepting what Flo said is accepting that smoking is addictive, rather than accepting that Flo said that smoking is addictive. So, accepting is a form of first-order engagement with what was said. It's therefore a pressing question for the proponent of the propositional knowledge account how ordinary speakers make the required transition from what they take in through understanding - according to that account, knowledge of what was said-to a form of engagement with what was said that can provide an appropriate basis for acceptance or rejection. That is, the proponent of the knowledge account must explain how one makes the required transition from second-order engagement to appropriate first-order engagement with what was said.

If the required result is to be secured in a way that supports the propositional knowledge account over alternatives, it must be secured on the basis of inference over known propositional contents. That is, the transition must be a matter of knowledge(or epistemic standing-) preserving inference. Articulating the required inference must proceed via instances of principles able to mediate between the proposition known through understanding — an instance of the proposition-schema: that Shas said that $p$ and the proposition accepted on that basis_an instance of: that $p$. The most natural principles able to mediate that transition are what I shall call saying-equivalence and propositional-equivalence:

(Saying-equivalence) $\quad S$ said that $p$ if and only if what $S$ said $=$ that $p$. (Propositional-equivalence) That $p$ is true if and only if $p$.

(As an alternative, the principles might be formulated as co-entailments, rather than bi-conditionals, and the discussion that follows reformulated mutatis mutandis.) By exploiting instances of the two principles, a subject, $A$, can effect instances of the following schematic transition (with the various principles and other sources of warrant that $A$ exploits in making steps in the transition recorded in parentheses):

(P1) A knows what $S$ said. [Via understanding, according to the propositional knowledge account.]

(P2) Aknows that what $S$ said is true. [Concessive assumption.]

(P3) $A$ knows that $S$ said that $p$. [From P1, analysis of knowing what $S$ said.]

(P4) $A$ knows that what $S$ said = that $p$. [From $\mathrm{P} 3$, saying-equivalence.]

(P5) $A$ knows that that $p$ is true. [P2, P4, substitution of identicals.]

(P6) $A$ accepts that $p$. [P5, propositional-equivalence.]

(P7) $A$ accepts what $S$ said. [P6, analysis of accepting what $S$ said.]

If that is the way that the proponent of the knowledge account seeks to ensure the transition from understanding to an appropriate target for acceptance, then they're required to view the two principles-saying-equivalence and propositionalequivalence - as available to, and exploited by, $A$. That is, they're required to take the principles to be cognized or acknowledged by $A$ with appropriate epistemic standing. The principles must either be objects of $A$ 's knowledge or be respected by knowledge sustaining transitions in $A$ 's thinking. And $A$ must exploit their cognition of the principles, through displaying a suitable sensitivity to the principles, in the course of 
coming to accept what they take in through understanding. If adherence to the principles is to deliver knowledge, then cognition of the principles must not be an idle wheel with respect to the required transitions. The point isn't of course that Amust consciously run through the steps of the proposed transition. Rather, the minimal point is that the course of $A$ 's thinking must be appropriately sensitive to the obtaining of the principles.

The objection to this treatment is not that the required principles are false. Rather, the objection is that it's implausible to suppose that an audience's capacity to exploit their understanding in order to accept what was said depends upon their exploiting such principles. The required principles are, ultimately, principles of semantic descent and, so, are required only because of the initial semantic ascent built into the propositional knowledge account of understanding. The propositional knowledge account overintellectualizes the warrant for testimony by requiring semantic ascent in its secondorder engagement with content, and then requiring principles of semantic descent in order to achieve the first-order engagement with content that is the product of successful uptake of testimony. A treatment able to avoid that inferential dogleg would clearly be preferable.

The entertaining account sustains such a treatment. Because the entertaining account avoids the semantic ascent built into the knowledge account, it has no need to exploit principles of semantic descent. Instead, it treats warrant as transmitted immediately from understanding what was said in an assertion to accepting it.

According to the entertaining account, a subject's understanding what was said is a matter of their entertaining what was said in a way that depends constitutively on its having been said, and in such a way as to put the suitably equipped in a position to know what was said. Thus, if someone moves reliably from so entertaining a propositional content to accepting it, then they will reliably be accepting precisely what was said. Furthermore, we have that understanding what was said presents an invitation to acceptance, so that it is of the nature of the attitude involved in understanding to underwrite immediate transitions to states of acceptance that depend constitutively on the initial understanding. Such transitions involve nothing more than a natural shift in attitude towards an entertained content, from merely entertaining to accepting it. (We might think of such shifts as somewhat akin to changes in degrees of belief, on a treatment of such changes as involving the modulation of particular states, rather than as involving the sequential replacement of one state by another.) Since we are allowing that our subject knows that what was said is true, it is clear that in reliably accepting the content that they understood to have been said, they are reliably exploiting that warrant. Moreover, they are doing so in a way that, at each stage, reliably depends on its having been said. Thus, the entertaining account can provide a plausible treatment of the transmission of warrant for accepting that what was said is true to accepting what was said.

The proposed treatment bears comparison with other similar cases. One such case is the acquisition of knowledge on the basis of seeing an object. In that case, seeing an object serves immediately to trigger the reliable exercise of conceptual abilities. Since the seeing can guarantee for one the presence of the seen object, the exercise of conceptual abilities can exploit that guarantee in order to constitute knowledge. The truth guarantee established by seeing underwrites a truth guarantee for appropriate 
concept application, and so provides an entitlement for that application. Another such case is the acquisition of knowledge via inference. In that case, knowing that $p$ and knowing that if $p$, then $q$, can serve immediately to sponsor accepting that $q$. The knowledge guarantees that it is true that $p$ and true that if $p$, then $q$. Competent deduction exploits those guarantees, together with the guarantee of truth preservation underwritten by appropriate sensitivity to the nature of the conditional, in order to guarantee the truth of what is accepted, and thus transmit an entitlement for that acceptance. In this case, the inference takes one immediately from merely entertaining the proposition that $q$, as the consequent of a known conditional, to accepting that $q$. The case is therefore closely akin to the proposed treatment, on which a form of entertaining that $p$ can immediately sponsor accepting that $p$, without exploiting additional inferential abilities (for relevant discussion, see Peacocke 2003, pp. 52-73).

The entertaining-based treatment in effect simulates the knowledge-based treatment. According to the entertaining account of understanding, understanding can make it possible for the suitably equipped to acquire knowledge about what was said. In order to do so, understanding must furnish the subject with suitable guarantees of truth. But knowledge about what was said can sponsor the transmission of such guarantees to states of accepting what was said. So, if understanding can guarantee the truth of views about what was said, then understanding can directly sponsor the transmission of those guarantees. For the capacity of knowledge to sponsor those guarantees depends only on the way in which it guarantees the facts, and not on the specific conceptual resources that it deploys. Any other state able to guarantee those facts-be it a state of seeing or a state of understanding — would serve just as well. In particular, the entertaining-based treatment performs the service at a lower cost.

Crucially, the proposed treatment draws only on capacities that are required for the distinctive form of entertaining of expressed content that the account takes to constitute accepting what was said on the basis of having understood it. Accepting what was said is a first order attitude to that which was said, rather than a second order attitude about what was said. Thus, in order to accept what was said, one need not possess the conceptual abilities required to think about what was said. The present treatment holds that the same is true of understanding what was said. Where what was said was that $p$, both understanding and acceptance require the ability to think that $p$, and so acceptance on the basis of understanding requires the same ability. Understanding requires the further ability to have that thinking triggered in the right way by confrontation with someone saying that $p$. But it requires no conceptual abilities that are not anyway required for accepting that $p$. And since it is of the nature of understanding to lead to acceptance, accepting that $p$ on the basis of understanding requires no additional powers. It therefore sustains an account of testimonial warrant that is less intellectually demanding than any treatment supported by the propositional knowledge account.

Thus, it is possible to give a treatment of the role of understanding testimonial warrant for accepting what was said that does not depend on the possession of abilities to think about what was said, or abilities to make competent inferences from knowledge about what was said, in order to accept what was said. Since the propositional knowledge account holds that understanding requires such abilities, it provides an over-intellectualized treatment of testimonial warrant. 


\section{Alternatives to the entertaining account}

There are other accounts that agree with the entertaining account in denying that understanding is a form of propositional knowledge. Comparison with some of those accounts may help to illuminate some of the distinctive features of the entertaining account. I'll focus on the accounts presented by Pettit (2002) and Fricker (2003). Both accounts agree with the entertaining account that understanding is not a form of propositional knowledge. However, attention to the central feature of the entertaining account - that is, its treatment of understanding as a first-order attitude to what was said-reveals critical ambiguities in their presentations. On one disambiguation, their accounts are less developed versions of the entertaining account. On the other disambiguation, they agree with the propositional knowledge account that understanding comprises attitudes about what was said, and so face the same objection from overintellectualization as that account.

\subsection{Pettit's proposal}

Pettit presents his positive proposal in the following passages:

When someone assertively utters the sentence 'there is water on Mars', it will seem to you as though the speaker said that there is water on Mars. As a competent speaker of English, you cannot help having this impression.... But that you have this impression is enough for you to count as understanding the word.... (Pettit 2002, p. 546).

Whatever turns out to be the nature of the psychological states that constitute our understanding of language, it is natural to suppose that those states are representational. The view that understanding is some sort of non-propositional knowledge implies that our understanding of a language consists in psychological states that are not representational, and specifically that they do not represent the semantic properties of the language. And nothing I have said here suggests that that is the case.... The point to emphasize is not that linguistic understanding is not propositional knowledge (in contrast with other sorts of knowledge) but rather that it is not propositional knowledge (in contrast with other propositional attitudes). The arguments presented here leave it open whether linguistic understanding is some other sort of propositional attitude. (Pettit 2002, pp. 548-549, his emphasis.)

Pettit's focus is on understanding word and sentence meaning, rather than understanding what was said, and we shouldn't assume that he intended to commit to any view about the latter. However, one natural extrapolation would include the view that understanding a sentence involves being disposed to understand what is said by uses of the sentence, where understanding what was said is characterized in the following way. First, in a case in which someone said that $p$, understanding what was said would consist in its seeming to one as though they said that $p$. Second, understanding what was said is a propositional attitude. Third, understanding what was said consists in psychological states that represent what was said. 
From the present perspective, the extrapolated proposal is underspecified at two key points. The first concerns the conditions in which its seeming as though someone said that $p$ would count as understanding what they said. Is it required that one's impressions correspond with what was in fact said? Is mere correspondence enough, or must additional conditions be imposed in order to rule out analogues of veridical hallucination? The entertaining account is shaped here by plausible connections between understanding and being in a position to know what was said. If the extrapolated proposal were developed in accord with the same constraints, it might become a version of the entertaining account. If not, then the proposal would need to deal differently with our natural expectation that those who understand what was said are typically in a position to know what was said.

The second way in which the account is underspecified concerns whether what is said is taken to figure in the propositional attitudes that constitute understanding in a first-order or a second-order way. If it figures in a first-order way, then the account agrees on that point with the entertaining account. If it figures in a second-order way - as suggested by the characterization of the operative seeming and the appeal to representing what was said-then the proposal would disagree with the entertaining account at the same fundamental point as the propositional knowledge view, and so would be subject to a version of the objection from over-intellectualization.

\subsection{Fricker's proposal}

Fricker seeks to provide an interlocking account of what it is to understand a language and what it is to understand what is said by uses of the language. On her view, understanding a language consists in possessing a certain type of reliable capacity to understand what is said by uses of the language. Understanding what was said by a particular use of the language consists in enjoying "a correct quasi-perceptual representation of the content and force" carried by the utterance, through exercise of the capacity that constitutes understanding the language (Fricker 2003, pp. 345-346). It would be consistent with the entertaining account to adopt Fricker's account of the way understanding a language is connected with understanding what was said. The two accounts disagree, if at all, only about the nature of states of understanding what was said.

Whether the accounts disagree about states of understanding depends on Fricker's more detailed characterization of the quasi-perceptual representations that she takes to constitute those states. These, she writes, are

...conscious mental states distinct from belief with three key perception-like properties: (1) phenomenologically they have the nature of experiences, perceptions of meaning; (2) where the hearer forms a belief about what is said, her understanding-experience will be the proximate (perhaps simultaneous) cause of this, and feature in the causal explanation of her belief; (3) alongside (2), in fluent language use understanding-experiences also play a key epistemic role in grounding perceptual beliefs. On the proposed account of how knowledge of what has been said is such, a hearer's understanding-experience of the meaning of an utterance she hears grounds her belief about what has been said, in a way 
exactly parallel to that in which visual experience, with its objective content, grounds visual perceptual beliefs. (Fricker 2003, p. 329, citing Brewer 1999 in connection with the way visual experience can ground beliefs.)

The entertaining account includes versions of (2) and (3). Whether the accounts agree about (1) depends most fundamentally on Fricker's account of the connection between her quasi-perceptions and what was said. If the quasi-perceptions have what was said as their first-order contents, then the accounts agree. If, by contrast, the quasi-perceptions have what was said only as their second-order contents - and, so, have contents that are about, rather than identical with, what was said - the accounts disagree, and Fricker's account would be subject to a version of the same charge of over-intellectualization as the propositional knowledge account.

Fricker's talk of quasi-perceptual representations of content, and her analogy with the objective content of visual experience, suggests that her quasi-perceptual states have contents that are about what was said. For those who hold that visual experience has objective content typically also hold (with Brewer 1999) that that content is about the things that are seen. On such a view, a visual experience of a cat would have an objective content the correctness of which was dependent on the presence and disposition of a cat. Similarly, a quasi-perception of what was said would have an objective content the correctness of which was dependent on the occurrence and content of an episode of speech. If so, the view would be relevantly similar to the propositional knowledge account, on which understanding what was said consists in knowledge with just such an objective content, and, so, would be subject to the same objection.

However, although the majority of Fricker's characterizations treat her quasiperceptions as second-order representations of what was said, some are ostensibly closer to the entertaining account:

...when one hears, with uptake - either literally, or in one's mind's ear, as it were - an utterance of a sentence of a language one is fluent in, this constitutes, cognitive-functionally speaking, an occurrence of the thought which is the meaning of that utterance, the proposition represented by it... the hearing [of the utterance] itself, when it is heard with 'uptake', constitutes a thought of the proposition which is the meaning of [the utterance]. [The utterance] itself is the vehicle in consciousness through entertaining which the subject thinks of that proposition. (Fricker 2003, pp. 360-361)

At first blush, this passage might seem to accord with the entertaining account. However, the evidence is mixed. Although Fricker appeals to the "occurrence of a thought which is the meaning of that utterance", she also characterizes the subject as thinking "of that proposition" (my emphasis), rather than simply entertaining the proposition. Furthermore, we noted earlier that it is consistent with a second-order treatment of understanding to allow that understanding entails a form of first-order entertaining of what was said (see again Burge 2005, 174ff). What is distinctive of the entertaining account is its commitment to the converse entailment: a distinctive form of first-order entertaining of what is said entails understanding. The balance of evidence suggests, therefore, that Fricker's account treats understanding as a form of second- 
order engagement with what was said. It is therefore subject to the objection from over-intellectualization. (Fricker's appeal to quasi-perceptual representations of content and force suggests that she may have rejected an entertaining account on the basis of the worry about force to which I responded at the end of Sect. 2.)

\section{Conclusion}

The ability to understand what was said is a central epistemic power. I've attempted to make some progress in uncovering the nature of its outputs, instances of understanding what was said. In Sect. 2, I presented a novel account of understanding what was saidthe entertaining account - according to which understanding is a distinctive attitude towards that which was said. In Sect. 3, I sought to test that account against its major competitor, the propositional knowledge account, by considering their respective treatments of the role of understanding in transmitting testimonial warrant. I argued that the treatment supporting the propositional knowledge account is over-intellectualized. The entertaining account underwrites a more economical treatment, a treatment better aligned with the minimal intellectual resources required for accepting what we are told. In Sect. 4, I considered two alternative accounts and argued that insofar as they treat understanding as an attitude about what was said, they are subject to the objections brought against the propositional knowledge account. I hope to have done enough to show that the entertaining account is worthy of further attention and that understanding what was said may be possible in the absence of propositional knowledge of what was said.

Acknowledgements I'm grateful to audiences at the University of Birmingham, King's College London, NYU, and Riga. I'm especially indebted, for discussion and comments, to Paul Boghossian, Bill Brewer, Stephen Butterfill, Thomas Crowther, Naomi Eilan, Paul Faulkner, Mitchell Green, Steven Gross, Christoph Hoerl, Hemdat Lerman, Stephen Neale, Dean Pettit, Jim Pryor, Stephen Schiffer, Barry C. Smith, Matthew Soteriou, Mark Textor, and Asa Wikforss.

Open Access This article is distributed under the terms of the Creative Commons Attribution 4.0 International License (http://creativecommons.org/licenses/by/4.0/), which permits unrestricted use, distribution, and reproduction in any medium, provided you give appropriate credit to the original author(s) and the source, provide a link to the Creative Commons license, and indicate if changes were made.

\section{References}

Arnold, A. (2013). Some evidence is false. Australasian Journal of Philosophy, 91, 165-172.

Brewer, B. (1999). Perception and reason. Oxford: Oxford University Press.

Burge, T. (2005). Truth, thought, reason: Essays on Frege. Oxford: Oxford University Press.

Campbell, J. (1982). Knowledge and understanding. Philosophical Quarterly, 32, 17-34.

Church, A. (1951). The need for abstract entities in semantic analysis. Proceedings of the American Academy of Arts and Sciences, 80(1), 100-112.

Davies, M. (1989). Tacit knowledge and subdoxastic states. In A. George (Ed.), Reflections on Chomsky (pp. 131-152). Oxford: Basil Blackwell.

Dummett, M. (1978). Frege's distinction between sense and reference, in his truth and other enigmas. London: Duckworth.

Dummett, M. (1991). The logical basis of metaphysics. Cambridge, MA: Harvard University Press. 
Dummett, M. (1993). Testimony and memory. In Z. van Straaten (Ed.), 1994 Philosophical subjects: Essays presented to P.F. Strawson (pp. 117-139). Oxford: Oxford University Press. Preprinted in his 1993 The Seas of Language. Oxford: Clarendon Press. References to the preprint.

Evans, G. (1982). The varieties of reference. Oxford: Clarendon Press.

Fitelson, B. (2010). Strengthening the case for knowledge from falsehood. Analysis, 70, 666-669.

Fricker, E. (2003). Understanding and knowledge of what is said. In A. Barber (Ed.), Epistemology of language (pp. 325-366). Oxford: Oxford University Press.

Ginet, C. (1980). Knowing less by knowing more. In P. A. French, T. E. Uehling Jr., \& H. K. Wettstein (Eds.), Midwest studies in philosophy. Studies in epistemology (Vol. V). Minneapolis: Minnesota University Press.

Glymour, C., \& Cooper, G. (1999). Computation, causation, and discovery. Cambridge, MA: MIT Press.

Gross, S. (2005). Linguistic understanding and belief. Mind, 114(453), 61-66.

Heck, R. G, Jr. (1995). A sense of communication. Mind, 104(413), 79-106.

Higginbotham, J. (1992). Truth and understanding. Philosophical Studies, 65, 3-16.

Hunter, D. (1998). Understanding and belief. Philosophy and Phenomenological Research, 58(3), 559-580.

Kalderon, M. E. (2011). Before the law. Philosophical Issues, 21(1), 219-244.

Karttunen, L. (1977). Syntax and semantics of questions. Linguistics and Philosophy, 1, 3-44.

King, J. (2002). Designating propositions. Philosophical Review, 111(3), 341-371.

King, J., Soames, S., \& Speaks, J. (2014). New thinking about propositions. Oxford: Oxford University Press.

Klein, P. (2008). Useful false beliefs. In Q. Smith (Ed.), Epistemology: New essays (pp. 25-62). Oxford: Oxford University Press.

Longworth, G. (2008a). Linguistic understanding and knowledge. Nô̂s, 42, 50-79.

Longworth, G. (2008b). Comprehending speech, philosophical perspectives. Philosophy of Language, 22, 297-331.

McDowell, J. (1994). Knowledge by hearsay. In B. K. Matilal \& A. Chakrabarti (Eds.), Knowing from words: Western and Indian philosophical analyses of understanding and testimony (pp. 195-224). Dordrecht: Kluwer. Reprinted in his 1998: 414-443.

McDowell, J. (1998). Meaning, knowledge, and reality. Cambridge, MA: Harvard University Press.

Moltmann, F. (2003). Propositional attitudes without propositions. Synthese, 135, 77-118.

Osherson, D. (1995). Probability judgment. In E. E. Smith \& D. Osherson (Eds.), Invitation to cognitive science: Thinking (2nd ed., pp. 35-75). Cambridge, MA: MIT Press.

Peacocke, C. (2003). The realm of reason. Oxford: Oxford University Press.

Pettit, D. (2002). Why knowledge is unnecessary for understanding language. Mind, 111(3), 519-550.

Pettit, D. (2005). Belief and understanding: A rejoinder to gross. Mind, 114(453), 67-74.

Pietroski, P. (2000). On explaining that. Journal of Philosophy, 97, 655-662.

Pryor, J. (2007). Reasons and that-clauses. Philosophical Issues, 17, 217-244.

Rosefeldt, T. (2008). 'That'-clauses and non-nominal quantification. Philosophical Studies, 137(3), 301333.

Schiffer, S. (2003). The things we mean. Oxford: Clarendon Press.

Warfield, T. (2005). Knowledge from falsehood. Philosophical Perspectives, 19, 405-416. 